\title{
Testing Models of MCT Reactivation vs. Duplex Formation in the Kumuan and Garwhal Himalaya, India
}

\author{
J ulien Célérier*, T Mark Harrison and William J Dunlap \\ Research School of Earth Sciences, The Australian National University, Canberra, ACT 0200, AUSTRALIA \\ * To whom correspondence should be addressed.E-mail: julien.celerier@anu.edu.au
}

\begin{abstract}
We present preliminary results of the thermochronologic, microstructural and metamorphic evolution of the Kumaun and Garhwal Himalaya in the vicinity of the Alaknanda and Bhagarathi rivers, northern India. Samples of quartzite, schist and gneiss were collected from the Lesser Himalayan and Greater Himalayan sequences to explore the sequence of thrusting. We find that within the duplex of Lesser Himalayan rocks (Srivastava and Mitra, 1994), microstructures suggest that temperatures (and/or strain rates) during deformation did not vary significantly in the transport direction. Thermometric estimates from carbonaceous material are consistent with this observation. In contrast, the upper Lesser Himalayan sequence and MCT zone show strong gradients in quartz microstructure, metamorphic grade, thermal structure and age of textural development, with extensive reworking of earlier kyanite grade fabrics. In order to assess the conditions and sequence of thrusting, within and beneath the MCT zone, a series of thermochronologic measurements (40Ar/
\end{abstract}

39Ar) on fabric-forming white micas have been made as well as a suite of thermometric analyses on carbonaceous material. Preliminary results indicate that thrust sheets immediately below the MCT zone cooled through the muscovite closure temperature as late as $4 \mathrm{Ma}$. Thermometric analyses on adjacent samples indicate peak metamorphic temperatures of $550^{\circ} \mathrm{C}$. Lesser Himalayan quartzites up to $30 \mathrm{~km}$ south of the MCT record $\mathrm{Ar} / \mathrm{Ar}$ ages of $\sim 20 \mathrm{Ma}$ and peak temperatures in the vicinity of $300^{\circ} \mathrm{C}$. Work aimed at understanding the significance of these early results in the context of activity along the MCT is ongoing.

\section{References}

Srivastava, Pand Mitra G. 1994. Thrust geometries and deep structure of the outer and Lesser Himalaya, Kumaon and Garhwal (India); implications for evolution of the Himalayan fold-and-thrust belt: Tectonics, v. 13, p. 89-109 